\title{
Factors Affecting Growth of Information Communication Technology Firms in Nairobi, Kenya
}

\author{
Duncan Mwangi Ikua \\ Kenya School of Government, P. O. Box 8475-00200, Nairobi, Kenya \\ Email: duncanza@gmail.com
}

Prof. G.S. Namusonge

Jomo Kenyatta University of Agriculture and Technology, School of Human Resource Development, P. O. Box 62000-00200, Nairobi, Kenya

Email: gsnamusonge@yahoo.co.uk

DOI: 10.6007/IJARBSS/v3-i7/58 URL: http://dx.doi.org/10.6007/IJARBSS/v3-i7/58

\begin{abstract}
Entrepreneurship plays an important role in the socio-economic development of the country. Its significance can be seen in terms of contribution towards economic growth, employment creation, poverty reduction and development of an industrial base. Kenya is going through a paradigm shift from an industry based economy to a knowledge based economy anchored on ICT. The government has reiterated the development of ICT industry in the country given its strategic importance. These commitments manifest in the various policies and strategies that the government has put in place over time, aimed at the growth and expansion of ICT in the country. Despite the policy and strategy pronouncements, there are various constraints that are currently facing the growth and expansion of ICT in the country especially amongst ICT providers.
\end{abstract}

This study sought to assess the factors that affect the growth of ICT firms in Kenya by focusing on the ICT providers in Nairobi. The Purpose of the study was to establish the factors affecting growth of ICT Firms in Nairobi. The study involved a case study of ICT firms in Nairobi. The target population constituted ICT service providers located in Nairobi. The study targeted 92 firms out of 304 registered ICT service providers in the CCK database. The sampling frame used was acquired from the CCK directory of licensed ICT providers 2012. Stratified random sampling technique was used based on categories of ICT service providers registered by CCK. Questionnaires were used to collect data from a sample of 92 ICT Firms. The respondents were owner/ managers and selected employees. The study findings indicate that access to markets significantly affects growth of ICT firms negatively or positively. Access to market information, The presence of a wide market for ICT products and services, ICT usage and penetration and presence of ICT-related services promote growth and expansion of ICT firms. Competition in the ICT sector inhibits growth of ICT firms. The study recommends the following: Pertaining access to markets; the government should undertake to make markets work. This can be achieved by promoting the number and competitiveness of ICT firms by reducing the cost of doing business and, generally, creating a more favourable environment for businesses to thrive 
while improving the quality of employment in the sector. The government should allocate at least 25 percent of its procurement requirements to the sector. The Government should encourage sub-contracting arrangements between large and medium firms, and the SMEs. Capacity building of SME Associations will further promote business linkages within the sector. The Government should restrict dumping of ICT products and facilitate marketing of SME products in both local and international markets.

Keywords: ICT firms, access to markets, Growth

\subsection{Introduction}

Entrepreneurs are individuals who discover market needs and launch new firms to meet those needs. They are risk takers who provide an impetus for change, innovation, and progress in economic life. The Small and Medium Enterprises (SMES) are businesses in both formal and informal sectors, classified into farm and non-farm categories employing 1-50 workers (GoK, 2005). These enterprises cut across all sectors of the Kenyan economy and provide one of the most prolific sources of employment creation, income generation and poverty reduction.

Today's business world has been deeply influenced by Information and Communication Technologies (ICT) and the application of ICT among business is widespread. ICTs are rapidly changing global production, work and business methods and trade and consumption patterns in and between enterprises and consumers. The Small and Medium Enterprises (SMEs) have been credited with enormous contribution to the growth of the developed economies of the world. In the same vein, the information and communication technologies (ICTs) and particularly the internet have played their own part in those economies. The American economy, the biggest economy in the world, depends largely on the success of SMEs for innovation, productivity, job growth and stability (Chandler, 1977). The rapid transformations of the high performing Asian countries such as India, Malaysia, Indonesia, Taiwan and Hong Kong have also been hailed as proof that SMEs are major catalysts to economic development. Their importance to any economy hinges on their ability to stimulate ingenious entrepreneurship, to provide employment to a greater number of people, to mobilize and utilize domestic savings and raw materials, to provide intermediate raw-materials or semiprocessed products to large scale enterprises and to curtail rural-urban migration. The SMEs provide the cornerstones on which any country's economic growth and stability rests. As the world economy continues to move toward increased integration as a result of advances in information communications technology, and the increasing reduction in trade barriers, some of the greatest opportunities for small businesses will arise from their ability to participate in the regional and international markets (Mutula \& Brakel, 2006).

The Kenya Vision 2030 envisages ICT as one of the key drivers of economic development as we strive to achieve the aspirations of the county's development plan. The SME sector is important in the social economic development of Kenya and is perceived as an engine for growth (GOK, 2008). However, SMEs seem ill equipped to confront the challenges of globalization, whose hallmark is Information Communication Technology (ICT) and innovation, a major determinant of competitiveness. 
At the turn of the year 2010-2011 the World Bank published a press release accompanying its December 2012 Kenya Economic Update that showed that the overall Kenyan economy was at a "Tipping Point". The report estimated 4.9 percent growth in 2010 and 5.3 percent in 2011. The report specifically identified the telecommunications revolution as a key driver to the economic growth of the country. "The growth in ICT is significant and has out-performed all other sectors over the last decade. Without ICT, Kenya's growth rate would have been only 2.8 percent since 2000, barely exceeding population growth". The report attributes the "explosive" growth in ICT to the liberalization of the telecommunications sector, which induced competition and innovation, resulting in considerable investment and job creation. The report argues that Kenya could develop into a regional hub of IT innovations and IT-enabled services due to its cost advantages, investment in enabling infrastructure including fiber optic cables and a well educated and urbanized labor force, (World Bank, 2011).

Kenya is home to a modest ICT/ICTE industry, most of which has emerged after the recent liberalization of the telecom sector. Leaving aside the vast group of distributors and resellers of IT equipment, which in some cases can hardly be included in the category, the Kenyan ICT/ICTE sector is mainly comprised of small enterprises active in fields such as software customization, web design, ICT value-added services and IT consultancy. Typically, the services provided are very basic. In addition, some hardware assembling activity was set up after the government lifted the import duty on parts, but the amount is still very limited. The export of services-in the form of outsourced processes - is also very limited. There are only a handful of active BPO firms and call centres.

Currently there are 304 ICT service providers in the register of unified licensing framework licensees by held CCK as at February 2012. Applications Service Provider (ASP) accounted for 92 firms, Telecommunications Equipment Vendors (TEV) 140 firms, Business Process Outsourcing Service Providers (BPO) 32 firms and Public Communication Centers 40 firms. The National ICT Strategy issued by the government in 2006, places particular emphasis on the enormous potential of this industry. Nevertheless, Kenya has yet to overcome the persistent weaknesses of its telecom infrastructures, and its lack of a reliable and cost-effective international connectivity.

\subsection{Problem Statement}

The core of entrepreneurship is technology and innovation which help in creating entrepreneurial firms. The remarkable growth of the Information and Communication Technology (ICT) sector over the last two decades has transformed many economies. The drivers of economic growth have become more information-intensive and less dependent on natural resources. Affordable access to high-quality ICTs has become a key priority for policymakers and businesses at large.

In Kenya, the government has reiterated the development of ICT industry in the country given its strategic importance. These commitments manifest in the various policies and strategies that the government has put in place over time, aimed at the growth and expansion of ICT in 
the country. These are contained in the various policy documents and budget speeches, as well as the Vision 2030 (GoK, 2008).

Despite the policy and strategy pronouncements, there are various constraints that are currently facing the growth and expansion of ICT in the country especially amongst ICT providers. Duncombe and Heeks (1999) notes that these range from financial, human resources, to infrastructural development and maintenance among others. Therefore, this study sought to analyze the factors that affect the growth of ICT firms in Kenya by focusing on the ICT providers in Nairobi.

\subsection{Literature Review}

\subsection{Theoretical Framework}

The study applied Timmons Model of Entrepreneurship and Mark Casson's Economic Theory of Entrepreneurship.

\subsubsection{Timmons Model of Entrepreneurship}

Timmons (2004) considers opportunities, teams, and resources as the three critical factors available to an entrepreneur and holds that success depends on the ability of the entrepreneur to balance these critical factors. Jeffery Timmons of Babson College in Massachusetts developed the Timmons Model of Entrepreneurship as his doctorate thesis at Harvard University. Further research and case studies have since then enhanced this model as a guide for entrepreneurs to increase their chances of success. The Timmons model bases itself on the entrepreneur. The entrepreneur searches for an opportunity, and on finding it, shapes the opportunity into a high-potential venture by drawing up a team and gathering the required resources to start a business that capitalizes on the opportunity. In the process of starting the business, the entrepreneur risks his or her career, personal cash flow and net worth. The model bases itself on the premise that the entrepreneur earns rewards in commensuration with the risk and effort involved in starting or financing the business.

The Opportunity Factor

The Timmons model of entrepreneurship believes that entrepreneurship is opportunity driven, or that the market shapes the opportunity. A good idea is not necessarily a good business opportunity and the underlying market demand determines the potential of the idea. An idea becomes viable only when it remains anchored in products or services that create or add value to customers, and remains attractive, durable, and timely.

Unlike conventional entrepreneurship models that start with a business plan and identify an opportunity, the Timmons model starts with a market opportunity. The business plan and the financing receive secondary importance, and come only after identification of a viable opportunity. The model holds that a sound business opportunity would readily receive financing, and identification of the opportunity first makes the business plan failure-proof.

\subsubsection{Mark Casson's Economic Theory}

Casson (2003) holds that entrepreneurship is a result of conducive economic conditions. In his book "Entrepreneurship, an Economic theory" he states the demand for entrepreneurship 
arises from the demand for change. Economic factors that encourage or discourage entrepreneurship include: taxation policy, industrial policy, easy availability of raw materials, easy access to finance on favourable terms, access to information about market conditions, availability of technology and infrastructure and marketing opportunities.

\section{Conceptual Framework}

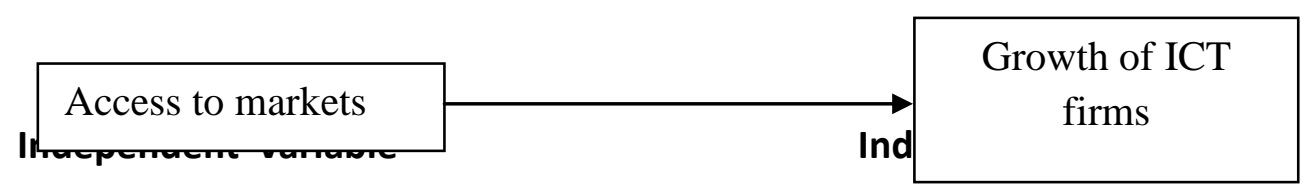

\subsection{Access to markets}

Miles (2001) notes that market-focused strategies allow governments to meet social and economic goals, such as increasing access to ICTs and revenue from telecommunication services. Miles observed that market reforms can boost productivity and profitability and stimulate investment while enhancing the performance of the ICT sector. The reform according to Miles includes: market liberalization and competition; private sector participation; and effective regulation. Liberalized markets are generally more efficient than markets under government control, and they are more likely to generate greater benefits for consumers and businesses.

In UNPAN (2005) it was noted competition may take many different forms, however, as the experience of Vietnam's alternative approach to sector reform that has boosted growth of ICT. In Vietnam, foreign investment in the ICT sector was allowed through Business Cooperation Contracts (BCCS), rather than direct equity stakes. This according UNPAN has seen the tremendous growth of ICT sector in the country. UNPAN (2005) however, cautions that while Vietnam's managed competition among government entities has contributed to its ICT sector growth and expansion, further liberalization needs to be pursued if it is to become a regional ICT hub. Vietnam's commitments include allowing a progressively higher degree of foreign participation, ending the requirement for BCCs and opening up markets to greater competition.

Evidence from liberalizing countries such as Kenya, Tanzania, Zimbabwe, and Ghana shows that after an initial burst of growth, economies with static capabilities slow down as their inherited advantages are exhausted (UNPAN, 2005). Without any strategic support from government, UNPAN noted countries find it difficult to bridge the gap between their skills, technologies, and scientific capabilities and those needed for international competitiveness.

According to UNPAN, this is one important reason why liberalization has had such poor results in sub-Saharan Africa. UNPAN notes that liberalization has also led to technological regression in many countries of Latin America, with relatively weak growth and competitiveness. The experience of the most successful developing countries in recent economic history (the newly industrialized economies of Asia) suggests that there is a major role for governments in providing the 'collective goods' (which includes ICT) needed for sustained development (UNPAN, 2005). 
Access to markets and marketing information is a severe constraint to SMEs development in Kenya. Overall, aggregate demand is low, markets are saturated due to dumping and overproduction, and in many cases markets do not function well due to lack of information and high transaction costs. Competition in some products is unfair, with imported goods finding their way into the local market without payment of statutory duties (GoK, 2005).

Many SMEs are also ill-prepared to compete in liberalized markets. Very few are capable of venturing into export markets and even fewer are able to tap the new market frontiers through electronic commerce. As a result, most SMEs are confined to very narrow local markets where intense competition drives prices down, resulting in very low profit margins. In many cases, the market mechanisms that can deal with these problems are either missing or weak. Also, a small capital base and limited technological sophistication confine SMEs to products and services, which cannot compete effectively in a globalized and competitive market environment due to quality limitations.

While the Government has made efforts to liberalize financial and product markets over the past decade, significant barriers to entry into certain markets still exist. There- are also high unit transaction costs for small volume producers due to their underlying low economies of scale. Specifically, public sector purchasing practices, where pre-qualification standards demand assurance of large supplies and proof of adequate financial resources to produce them, have, for the most part, excluded SMEs from the large public sector market.

Although the flow of information on SME markets has slightly improved, many SMEs still do not know where and how to access existing and relevant marketing information. As a result, the majority rely on informal feedback from customers. Competitiveness of the SMEs remains weak due to poor product quality, packaging, advertising and distribution.

\subsection{Measurement of growth}

Globally, SMEs are perceived as the engine of economic growth and for promoting equitable development. SMEs are the starting point of development in countries desiring industrialisation. Adjusting to changes in the organisational environment such as Globalisation, political, social, economic and technological factors pose a great challenge to SMEs, which limits their ability to maintain their position against larger organisations (Omar et al, 2009). Increasing business competition, in particular against large and modern competitors, has put SMEs in a very vulnerable position, (Indarti \& Langenberg, 2004).

The SME sector is fast growing. According to the 1999 MSE Baseline Survey, the number of enterprises in the sector has grown from 910,000 in 1993 to about 1.3 million in 1999. Out of the 1.3 million enterprises in 1999, about $66 \%$ were located in the rural areas while women owned accounted for $48 \%$ of the enterprises. According to the Survey, $64.3 \%$ of the MSEs in trade, $14.8 \%$ in services, $13.4 \%$ are in manufacturing while $7.7 \%$ are involved in other activities. Apparently, out of the $48 \%$ enterprises owned by women $75 \%$ are in trade and service subsectors. The sector employed 2.4 million persons. This has increased to 5.1 million persons in 2002 as per the 2003 Economic Survey and translates to 675,000 jobs per year. The level of 
employment within SMEs in 2002 accounted for over $74.2 \%$ of the total number of persons engaged in the country. This is evidence that, with proper development strategies, the sector is capable of providing and surpassing the Government's target of creating 500,000 jobs per year.

There are many constraints that hinder new business start-ups. Empirical studies (Kibera \& Kibera, 1997) have identified the factors that are generally agreed on as the constraints to the growth of SMEs in Africa. The factors according to Garikai (2011) include lack of market opportunity, access to finance, enabling environment, market information, and managerial skills. Other key challenges faced by SMEs include increase in raw material prices, rising overhead costs and cash flow problems. Jun \& Lljun (2007) identified the factors affecting enterprise growth to be: strategic thinking of entrepreneurs, employment level of entrepreneurs, social responsibility of entrepreneurs, scale of capital, level of profit, corporate culture and entrepreneurial decision-making mode. Some studies have also shown high interest rates as the main hurdle facing SMEs but this still needs further investigation since not all SMEs rely on credit. In this study, growth was measured in terms of number of employees engaged and duration in operation in years of the ICT firms. A higher number of staff engaged indicates good growth potential. A longer duration in operations of the ICT firms depicts stability and growth potential.

\subsection{Critique of Literature Relevant to this Study}

Sewe (2010) in his study on factors affecting growth of ICT sector in Kenya focused on industry factors, economic factors and policy and strategy factors. The study identified various impediments towards the growth and expansion of the ICT sector in the country. These are in terms of policies and strategies, economic factors as well as industry factors. In terms of economic factors, various factors were identified to be affecting the expansion and growth of ICT. These include tax incentives, incentives for investment in the ICT sector and access to current information on ICT. Other factors identified included; regulatory requirements by the government which inhibits investment in ICT, license fees and license requirements and political risks. On the other hand, the study identified various industry factors as inhibiting growth and expansion of the ICT sector. These include interconnection framework that was perceived to be unfavorable, lack of innovation and human capacity building strategies and existence of an adequate pool of highly trained skilled labor. Others include lack of proper training, inadequate management skills among senior managers, high interconnection charges, poor organizational culture, low adoption of technological skills, and low ICT usage and penetration habits among others.

Various policy and strategy supported factors were identified. These range from Licensing regulations, procedures and process as the most important, followed by ICT laws, uncoordinated government support of ICT innovation, diffusion, transfer and adoption by stakeholders, allocation of adequate bandwidth, sloppy conducive policy environment, lack of ICT policy as well as multiple regulatory institutions, non-harmonized and standardized ICT infrastructure, ineffective and fair regulation of the ICT sector, harmonized and standardized ICT access methods, ICT regulatory measures. The study failed to lay an emphasis on the role of the key enterprise success determinants namely access to finance, access to markets and policy 
environment. This study will strive to address the role of these factors in determining the growth of ICT firms in Nairobi.

\subsection{Research Design}

This study adopted a descriptive research based on case study. According to Saunders (2009), key features of case studies include; they are popular in business research, they are perceived as authoritative, structured observation and interviews can be used, they allow collection of quantitative data, data collected can be analyzed quantitatively and the approach gives the researcher independence. In this study the target population constituted ICT service providers located in Nairobi. The study targeted 92 firms out of 304 registered ICT service providers in the CCK database. This represents $30 \%$ of the total population. According to Mugenda (2003), a sample of $30 \%$ is favourable and adequately representative of the entire population.

The sampling frame was acquired from the Communications Commission of Kenya (CCK) directory of Licensed ICT providers 2012. The CCK is the regulatory authority established under the Ministry of Information and Communication that regulates ICT industry in the country.

Stratified random sampling technique was used based on categories of ICT service providers registered by CCK. The population was divided into relatively homogeneous groups called strata. Each stratum was selected randomly. Elements from each stratum were then combined to form the overall sample. This technique gives all the subjects an equal chance and also reduces bias and errors. This was achieved using a web based random number generator. The researcher used questionnaires - they offer well planned and focused data and are ideal for a large group of respondents within a short time and limited budget. Biases and prejudices in responses are also reduced or avoided. The researcher also prepared a budget and a work plan that were used as a guide during the actual research.

Using the case study methodology applied in this study, questionnaires were used to collect data from a total of 92 firms in Nairobi. Each item in the questionnaire is developed to address a specific objective or research question of the study. Secondary data was sourced from documentary review from CCK periodicals and reports, Government of Kenya policy documents such as Sessional Paper No. 2 of 2005, Kenya Vision 2030 and academic journals.

The provisional draft of the questionnaire was pre-tested on a pilot group of ICT firms in Mombasa similar to the sample to which the questionnaire was administered. The pilot run provided a check on the feasibility of the proposed procedure for coding data and show up flaws and ambiguities. It also yielded suggestions for improvement.

Quantitative data analysis was used in the study. Data collected was coded and analyzed using SPSS version 20 and Microsoft Excel 2007. Analyzed data was presented using frequency distribution tables, cross tabulations and graphical method using charts and graphs. Descriptive Statistics using cross tabulation was used to describe the relationship between the independent and dependent variables.

\subsection{Research Findings and Discussions}

\subsection{Access to markets}

The variable was used to measure the effect of access to markets on growth of ICT firms using different parameters such as access to market information, market for ICT products and 
services, competition in the ICT sector, ICT usage and penetration, ICT-related services and barriers to market access. The results are presented using cross tabulations to indicate the relationship between market access and growth of ICT firms.

\subsubsection{Access to market information}

The table below summarizes findings on access to market information and its effect on growth of ICT firms in Nairobi.

Table 4.1 Access to market information

Access to market information

No. of employees * market info Cross tabulation [count, total \%]

\section{Market information}

\begin{tabular}{llllll} 
& & Disagree & Agree & Strongly agree & Total \\
\hline \multirow{3}{*}{ No_of employees } & \multirow{2}{*}{$1-10$} & 3 & 32 & 14 & 49 \\
& & $4.2 \%$ & $45.1 \%$ & $19.7 \%$ & $69.0 \%$ \\
& \multirow{2}{*}{$11-50$} & 1 & 10 & 7 & 18 \\
& & $1.4 \%$ & $14.1 \%$ & $9.9 \%$ & $25.4 \%$ \\
& \multirow{2}{*}{$51-100$} & 0 & 4 & 0 & 4 \\
& & $0.0 \%$ & $5.6 \%$ & $0.0 \%$ & $5.6 \%$ \\
\hline \multirow{2}{*}{ Total } & & 4 & 46 & 21 & 71 \\
& & $5.6 \%$ & $64.8 \%$ & $29.6 \%$ & $100.0 \%$
\end{tabular}

The table above shows that $29 \%$ of the respondents strongly agreed that access to market information affects access to markets by ICT firms ultimately affecting their growth. $65 \%$ agreed with the statement and $6 \%$ disagreed. Although the flow of information on MSE markets has slightly improved, many MSEs still do not know where and how to access existing and relevant marketing information. As a result, the majority rely on informal feedback from customers. Competitiveness of the MSEs remains weak due to poor product quality, packaging, advertising and distribution (GOK, 2005).

\subsubsection{Market for ICT products and services}

The table below summarizes findings on market for ICT products and services and its effect on growth of ICT firms in Nairobi.

Table 4.2 Market for ICT products and services Market for ICT products and services

\begin{tabular}{lcccccc}
\hline $\begin{array}{l}\text { No_of employees * Market_ICT products Cross tabulation [count, total \%] } \\
\text { Market_ICT products }\end{array}$ & & & \\
& Disagree & Uncertain & Agree & Strongly Agree & Total \\
\hline No_of & \multirow{2}{*}{$\begin{array}{l}\text { N-10 } \\
\text { employees }\end{array}$} & 6 & 2 & 16 & 25 & 49 \\
\hline
\end{tabular}




\begin{tabular}{llllll}
\hline \multirow{2}{*}{$11-50$} & 3 & 2 & 2 & 11 & 18 \\
& $4.2 \%$ & $2.8 \%$ & $2.8 \%$ & $15.5 \%$ & $25.4 \%$ \\
\multirow{2}{*}{$51-100$} & 0 & 0 & 4 & 0 & 4 \\
& $0.0 \%$ & $0.0 \%$ & $5.6 \%$ & $0.0 \%$ & $5.6 \%$ \\
\hline \multirow{2}{*}{ Total } & 9 & 4 & 22 & 36 & 71 \\
& $12.7 \%$ & $5.6 \%$ & $31.0 \%$ & $50.7 \%$ & $100.0 \%$
\end{tabular}

The above indicates that $51 \%$ of the respondents strongly agreed that presence of a wide market for ICT products and services affects growth of the firms, 31\% agreed with the statement, $5 \%$ were uncertain and $13 \%$ disagreed. With Kenya's economy going through a paradigm shift from an industry based economy to an information based economy, there is bound to be a wide market for ICT products. Kenya is well known globally as a leader in mobile technology innovation through the M-PESA product (GOK, 2013).

\subsubsection{Competition in the ICT sector}

The table below summarizes findings on competition in the ICT sector and its effect on growth of ICT firms in Nairobi.

Table 4.3 Competition in the ICT sector

\begin{tabular}{|c|c|c|c|c|c|c|c|}
\hline \multicolumn{8}{|c|}{ No_of employees $*$ Competition Cross tabulation [count, total \%] } \\
\hline & & \multicolumn{6}{|c|}{ Competition } \\
\hline & & $\begin{array}{l}\text { Strongly } \\
\text { Disagree }\end{array}$ & Disagree & Uncertain & Agree & $\begin{array}{l}\text { Strongly } \\
\text { Agree }\end{array}$ & Total \\
\hline \multirow{6}{*}{$\begin{array}{l}\text { No_of } \\
\text { employees }\end{array}$} & \multirow{2}{*}{$1-10$} & 3 & 8 & 7 & 19 & 12 & 49 \\
\hline & & $4.2 \%$ & $11.3 \%$ & $9.9 \%$ & $26.8 \%$ & $16.9 \%$ & $69.0 \%$ \\
\hline & \multirow{2}{*}{$11-50$} & 6 & 5 & 3 & 4 & 0 & 18 \\
\hline & & $8.5 \%$ & $7.0 \%$ & $4.2 \%$ & $5.6 \%$ & $0.0 \%$ & $25.4 \%$ \\
\hline & \multirow{2}{*}{$51-100$} & 0 & 3 & 1 & 0 & 0 & 4 \\
\hline & & $0.0 \%$ & $4.2 \%$ & $1.4 \%$ & $0.0 \%$ & $0.0 \%$ & $5.6 \%$ \\
\hline & \multirow{2}{*}{ Total } & 9 & 16 & 11 & 23 & 12 & 71 \\
\hline & & $12.7 \%$ & $22.5 \%$ & $15.5 \%$ & $32.4 \%$ & $16.9 \%$ & $100.0 \%$ \\
\hline
\end{tabular}

The crosstab above depicts that $22.5 \%$ of the respondents disagreed with the statement that Competition in the ICT sector inhibits growth of ICT firms, $12.7 \%$ strongly disagreed, $15.5 \%$ were uncertain, $16.9 \%$ strongly agreed and $32.4 \%$ agreed with the statement. Competition inhibits growth of ICT firms. With competition, incidences of price competition are bound to affect the growth and expansion of the firms. As revealed by Scarpetta et al (2002), entry of new firms and the exit of declining firms, are partly due to more productive firms gaining 
market shares. Scarpetta et al (2002) also observed that the entry of new firms is particularly important, as they strive to increase their market share which has some negative implication on the existing ones.

\subsubsection{ICT usage and penetration}

The figure below summarizes findings on ICT usage and penetration and its effect on growth of ICT firms in Nairobi.

Table 4.4 ICT usage and penetration

\begin{tabular}{|c|c|c|c|c|c|}
\hline \multicolumn{6}{|c|}{ No_of employees * Usage and penetration Cross tabulation [count, total \%] } \\
\hline & & \multicolumn{4}{|c|}{ Usage and penetration } \\
\hline & & Uncertain & Agree & Strongly Agree & Total \\
\hline \multirow{6}{*}{ No_of employees } & \multirow{2}{*}{$1-10$} & 5 & 30 & 14 & 49 \\
\hline & & $7.0 \%$ & $42.3 \%$ & $19.7 \%$ & $69.0 \%$ \\
\hline & \multirow{2}{*}{$11-50$} & 3 & 8 & 7 & 18 \\
\hline & & $4.2 \%$ & $11.3 \%$ & $9.9 \%$ & $25.4 \%$ \\
\hline & \multirow{2}{*}{$51-100$} & 0 & 4 & 0 & 4 \\
\hline & & $0.0 \%$ & $5.6 \%$ & $0.0 \%$ & $5.6 \%$ \\
\hline & \multirow{2}{*}{ Total } & 8 & 42 & 21 & 71 \\
\hline & & $11.3 \%$ & $59.2 \%$ & $29.6 \%$ & $100.0 \%$ \\
\hline
\end{tabular}

The table above shows that $59.2 \%$ of the respondents agreed that ICT usage and penetration affects growth and expansion of ICT, $29.6 \%$ strongly agreed, $11.3 \%$ were uncertain and $6 \%$ disagreed with the statement. It can therefore be deduced that, ICT usage and penetration significantly affects growth of ICT firms. High usage of ICT services promotes growth of ICT firms as they register remarkable turnover. Low usage of ICT services leads to low growth levels of ICT firms. 


\subsubsection{ICT-related services}

The table below illustrates findings on how ICT-related services affect growth of ICT firms.

Table 4.5 ICT-related services

ICT-related services

\begin{tabular}{|c|c|c|c|c|c|c|}
\hline \multicolumn{7}{|c|}{ No_of employees * ICT_Related_Services Cross tabulation [count, total \%] } \\
\hline & & \multicolumn{5}{|c|}{ ICT_Related_Services } \\
\hline & & \multirow[t]{2}{*}{ Disagree } & \multirow[t]{2}{*}{ Üncertain } & \multirow[t]{2}{*}{ Agree } & \multicolumn{2}{|l|}{ Strongly Agree } \\
\hline & & & & & & Total \\
\hline \multirow{6}{*}{ No_of employees } & \multirow{2}{*}{$1-10$} & 4 & 4 & 27 & 14 & 49 \\
\hline & & $5.6 \%$ & $5.6 \%$ & $38.0 \%$ & $19.7 \%$ & $69.0 \%$ \\
\hline & \multirow{2}{*}{$11-50$} & 0 & 0 & 11 & 7 & 18 \\
\hline & & $0.0 \%$ & $0.0 \%$ & $15.5 \%$ & $9.9 \%$ & $25.4 \%$ \\
\hline & \multirow{2}{*}{$51-100$} & 0 & 0 & 3 & 1 & 4 \\
\hline & & $0.0 \%$ & $0.0 \%$ & $4.2 \%$ & $1.4 \%$ & $5.6 \%$ \\
\hline \multirow{2}{*}{\multicolumn{2}{|c|}{ Total }} & 4 & 4 & 41 & 22 & 71 \\
\hline & & $5.6 \%$ & $5.6 \%$ & $57.7 \%$ & $31.0 \%$ & $100.0 \%$ \\
\hline
\end{tabular}

The table shows that $31 \%$ of the respondents strongly agreed that presence of ICT-related services promote growth and expansion of ICT firms , 58\% agreed, $6 \%$ were uncertain and 5\% disagreed with the statement. The presence of ICT related services has gone a long way in stimulating growth of ICT firms. Most of the services are complementary, for instance, computer hardware resellers work with software resellers and mobile phone resellers work closely with accessory resellers.

\subsection{Growth}

In the study, growth was measured in terms of number of employees engaged and duration in operation in years of the ICT firms.

\section{Duration_Operations * No_of employees Crosstabulation}

\begin{tabular}{clllll}
\hline & & \multicolumn{2}{l}{ No_of employees } & \multicolumn{2}{c}{ Total } \\
& & $1-10$ & $11-50$ & $51-100$ & \\
\hline \multirow{5}{*}{ Duration_Operations } & less than 1 year & 7 & 0 & 0 & 7 \\
& $1-5$ years & 15 & 10 & 0 & 25 \\
& 6-10 years & 23 & 2 & 0 & 25 \\
& $11-15$ years & 1 & 5 & 4 & 10 \\
& 15 and above & 3 & 1 & 0 & 4 \\
\hline Total & 49 & 18 & 4 & 71
\end{tabular}


A higher number of staff engaged indicates good growth potential. A longer duration in operations of the ICT firms depicts stability and growth potential.

\subsection{Summary, Conclusions and Recommendations \\ 5.1 Summary}

\subsubsection{Access to markets}

Findings regarding access to markets indicate that, access to market information, the presence of a wide market for ICT products and services, ICT usage and penetration and presence of ICTrelated services promote growth and expansion of ICT firms. However, competition in the ICT sector inhibits growth of ICT firms.

\subsubsection{Growth}

There is a direct relationship between the number of years in operation of ICT firms and the number of employees engaged. The findings indicate that, $69 \%$ of the firms engaged $1-10$ employees, 25\% 11-50 employees and only 6\% engaged 51-100 employees. This data indicates that $69 \%$ of the firms prefer to remain small and are apprehensive of expansion by employing more staff. In Kenya, number of employees engaged is one of the parameters used to measure growth of firms. The average Kenyan MSE employs 1 - 2 workers while over 70 percent employ only one person.

It also emerged that, $10 \%$ of ICT firms have been in business for less than a year, 35\% for 1-5 years, $35 \%$ for $6-10$ years, $14 \%$ for $11-15$ years and $6 \%$ for 15 years and above. Considering growth patterns of Kenyan SMEs it is clear that most of the ICT firms have weathered the storm and seen their third birthday indicating stability and growth potential. According to research findings, SMEs have high mortality rates with most of them not surviving to see beyond their third anniversaries. This phenomenon has made it difficult for MSEs to graduate into medium and large-scale enterprises, thus the "missing middle".

\subsection{Conclusion}

The study indicates that majority of the respondents agreed that presence of a wide market for ICT products and services, ICT usage and penetration and presence of ICT-related services promote growth and expansion of ICT firms. There was also consensus that competition in the ICT sector inhibits growth of ICT firms.

\subsection{Recommendations}

The government should allocate at least 25 percent of its procurement requirements to the sector. To effect this, the Ministry of Finance should adjust public tendering procedures to promote the participation of SMEs in the procurement process. In the case of large tenders, the Government should encourage the formation of SME consortia capable of registering group bids. The Government should encourage sub-contracting arrangements between large and medium firms, and the SMEs. This will be achieved through provision of incentives such as tax rebates and duty waivers to encourage the large firms to participate in the arrangement. The sub-contracting arrangement will be done in consultation with the Kenya Bureau of Standards for quality assurance. Capacity building of MSE Associations will further promote business linkages within the sector.

\section{ACKNOWLEDGEMENT}

I would like to recognize the input of my supervisor, Professor G.S Namusonge for his guidance when I was undertaking my Research Project. A Special thank you also goes to the MSc. Entrepreneurship class of May 2011 for their moral support and encouragement. A special 
tribute goes to my wife, Sue and my son, Gabriel for their moral support and my employer, Ministry of Public Service for financial support during my studies. May God bless you abundantly.

\section{REFERENCES}

Casson, M. (2003). The Entrepreneur: An Economic Theory .University of Illinois at UrbanaChampaign's Academy for Entrepreneurial Leadership Historical Research Reference in Entrepreneurship. Available at SSRN: http://ssrn.com/abstract=1496173

Chandler, A.D. 1977. Information technology: the visible and new competitive weapon. Cambridge: Belknap press.

Duncombe, R., \& Heeks, R., (2005). "Information, ICTs and Small Enterprise: $\quad$ Findings from Botswana", Development Informatics, Working Paper Series, Institute for Development Policy and Management, University of Manchester.

Garikai, B.W. (2011). Growth of SMEs in Developing Nations: Special Reference to

AGOA. COMESA, Lusaka. Zambia.

Government of Kenya (2005). Development of Micro and Small Enterprises for Wealth and Employment Creation for Poverty Reduction: Sessional Paper No. 2 of 2005. Government Printer. Nairobi, Kenya.

Government of Kenya (2008). Kenya Vision 2030; The Popular Version. Government Printer. Nairobi, Kenya.

Government of Kenya (2013). National Information \& Communications Technology (ICT) Master plan 2013-2017. Kenya ICT Board. Government Printer. Nairobi, Kenya.

Indarti, N. \& Langenberg, M. (2004). Factors Affecting Business Success among SMEs: Empirical Evidences from Indonesia. University of Twente, Enschede, Netherlands.

Jun MI and LIjun CAO (2007). "Study on the Ecological Mechanism of Growth of SMEs," School of Management, Shanxi University, Taiyuan, P.R.China.

Kibera and Kibera (1997). Constraints to Small Business Growth: Entrepreneurship and Small Business Growth in Uganda. Makerere University. Kampala.

Miles, P. (2001). Globalization-Economic Growth and Development and Development Indicators, Planet Papers, Oxford Press, New York.

Mugenda, O.M. \& Mugenda, A.G. (2003). Research Methods: Quantitative and Qualitative approaches. ACTS Press. Nairobi. 
Omar, S. et al (2009). "The Background and Challenges Enterprises. A Human Resource Development of Business and Management. October, 2009.95. Vol. 4. No. 10.

Saunders, M. et al (2009). Research Methods for Business Students. Harlow: Prentice Hall. Upper Saddle River, New Jersey, USA.

Scarpetta, S. et al (2002). The Role of Policy and Institutions for Productivity and Firm Dynamics: Evidence from Micro and Industry Data. Economics Department Working Papers, No. 329. OECD. Paris.

Sewe (2010). Factors affecting the strategic growth of Information Communication Technology (ICT) in Kenya. United States International University. Nairobi.

Timmons, J. et al. (2004). Business Plans That Work: A Guide for Small Business. McGraw Hill.

UNPAN (2005). "Global E-government Readiness Report: From E-government to E-Inclusion, UNPAN, Geneva

UNPAN (2005). "Global E-government Readiness Report: From E-government to E-Inclusion, UNPAN, Geneva

World Bank (2012). Kenya Economic Update.. Accessed on http://www.worldbank.org/en/news/press-release/2012/12/05/energizing-kenya-seconomy-and-creating-quality-jobs on 23 October 2012. 